\title{
Decadal Variability in the Large-Scale Sea Surface Height Field of the South Pacific Ocean: Observations and Causes
}

\author{
Bo Qiu And Shuiming Chen \\ Department of Oceanography, University of Hawaii at Manoa, Honolulu, Hawaii
}

(Manuscript received 2 August 2005, in final form 6 February 2006)

\begin{abstract}
Large-scale sea surface height (SSH) changes in the extraequatorial South Pacific Ocean are investigated using satellite altimetry data of the past $12 \mathrm{yr}$. The decadal SSH signals in the 1990s were dominated by an increasing trend in the $30^{\circ}-50^{\circ} \mathrm{S}$ band and a decreasing trend in the central South Pacific Ocean poleward of $50^{\circ} \mathrm{S}$. In recent years since 2002 there has been a reversal in both of these trends. Spatially varying low-frequency SSH signals are also found in the tropical region of $10^{\circ}-25^{\circ} \mathrm{S}$ where the decadal SSH trend is negative in the eastern basin, but positive in the western basin. To clarify the causes for these observed spatially varying SSH signals, a 11/2-layer reduced-gravity model that includes the wind-driven baroclinic Rossby wave dynamics and the responses forced by SSH changes along the South American coast was adopted. The model hindcasts the spatially varying decadal trends in the midlatitude and the eastern tropical regions well. Accumulation of the wind-forced SSH anomalies along Rossby wave characteristics is found to be important for both previously reported long-term trends and their reversals in recent years. The boundary forcing associated with the time-varying SSH signals along the South American coast is crucial for understanding the observed SSH signals of all time scales in the eastern tropical South Pacific basin, but it has little impact upon the midlatitude interior SSH signals.
\end{abstract}

\section{Introduction}

High-quality sea surface height (SSH) measurements from the Ocean Topography Experiment (TOPEX)/ Poseidon (T/P), Jason-1, and European Remote Sensing $(E R S)-1 / 2$ satellites over the past 12 yr have provided the oceanography community with an unprecedented opportunity to study the variability of the world's ocean circulations. In addition to being a useful means to monitor the global SSH field on a temporally repetitive basis, the decade-long altimeter data have also become instrumental in clarifying the dynamics underlying many of the observed circulation changes. In this study, we will focus on the low-frequency SSH signals in the extraequatorial South Pacific Ocean from $10^{\circ}$ to $55^{\circ} \mathrm{S}$.

Several aspects of the low-frequency circulation changes in the South Pacific Ocean have been investigated in recent years. By combining repeat XBT and

Corresponding author address: Dr. Bo Qiu, Department of Oceanography, University of Hawaii at Manoa, 1000 Pope Road, Honolulu, HI 96822.

E-mail: bo@soest.hawaii.edu
T/P altimetric data, McCarthy et al. (2000) examined the SSH and thermocline changes along $\sim 30^{\circ} \mathrm{S}$ for the period of 1993-98. They detected a spinup in the South Pacific subtropical gyre based on Sverdrup transport and stressed the potential importance of mass storage during the gyre's spinup. A thorough examination of the South Pacific subtropical gyre spinup on the decadal time scale was conducted recently by Roemmich et al. (2006). By synthesizing datasets from satellite altimetry, the World Ocean Circulation Experiment (WOCE) hydrographic-float surveys, repeat hydrographic transects, and Argo profiling floats, they showed that the decadal SSH variability of the South Pacific subtropical gyre detected by the satellite altimetric measurements reflects a dynamic signal extending from the sea surface to depths of at least $1800 \mathrm{~m}$. Regarding the cause for the gyre spinup, Roemmich et al. (2006) suggested the decadal surface wind variability associated with the Southern Hemisphere annular mode (SAM) as the likely candidate.

The large-scale, low-frequency SSH changes in the South Pacific Ocean can be succinctly described by the map of the linear SSH trend over the past $12 \mathrm{yr}$ (Fig. 1). 


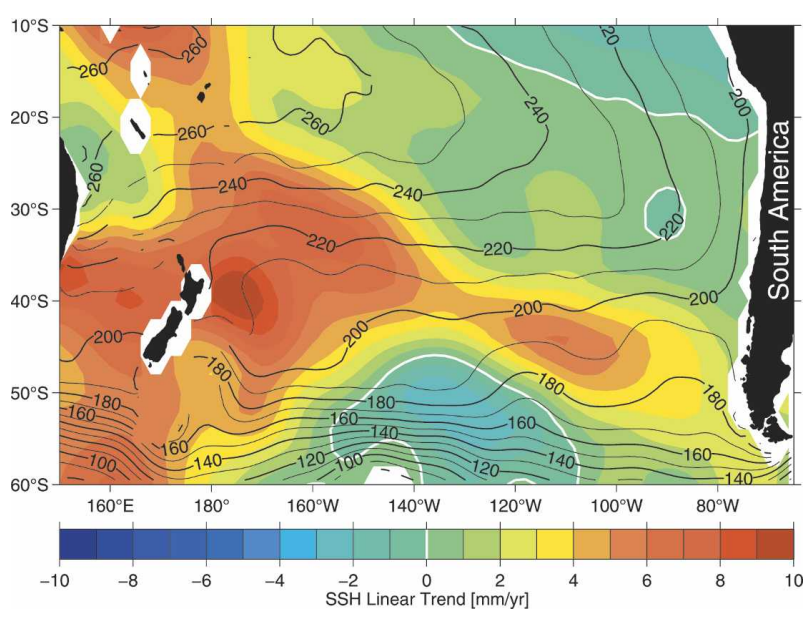

FIG. 1. Linear trend in the altimetrically derived SSH field from October 1992 to December 2004. Black contours denote the climatological sea surface dynamic height field (0-2000 dbar) from World Ocean Atlas 2001 (WOA01; Conkright et al. 2002) (cm).

Except for the eastern tropical South Pacific and a localized region in the central South Pacific poleward of $50^{\circ} \mathrm{S}$, an increase in SSH over nearly the entire South Pacific basin is obvious. The largest increasing trend occurs east of New Zealand with a rate exceeding 10 $\mathrm{mm} \mathrm{yr}^{-1}$. Notice that pictures similar to Fig. 1 have been published by investigators interested in the topic of global mean sea level rise (e.g., Cabanes et al. 2001; Cazenave and Nerem 2004; Church et al. 2004; Willis et al. 2004). For the period of the past decade, these studies show that the South Pacific Ocean has the most prominent, increasing SSH trend among the World Ocean basins.

While the linear trend of the SSH variability has been emphasized in the aforementioned studies of the South Pacific Ocean, inspection of more recent SSH data reveals that the large-scale SSH signals have more of an oscillatory nature. In addition, a look at Fig. 1 indicates that the decadal SSH trends observed in the South Pacific Ocean are by no means spatially uniform. As we noted above, there are geographical regions where SSH is detected to have a decreasing linear trend. We believe that an understanding of these spatially nonuniform and temporally modulating SSH signals in the South Pacific Ocean is important, because it can shed light on the cause of the previously reported linear trend signal as well. The objective of this study is to first describe the spatiotemporally varying SSH signals based on satellite altimetry data. The second objective is to provide a dynamic framework that explores the causes of the observed SSH signals. In particular, the importance of Rossby wave dynamics will be compared with that of local Ekman pumping dynamics in determining the large-scale SSH signals. The relative importance of the $\mathrm{SSH}$ anomalies forced in the interior ocean versus those forced remotely along the eastern boundary waveguide will also be considered.

\section{Altimeter data and SSH changes in the South Pacific Ocean}

For this study we use the global SSH anomaly dataset compiled by the Collecte Localisation Satellites (CLS) Space Oceanography Division of Toulouse, France. The dataset merges the T/P, Jason-1, and ERS-1/2 along-track SSH measurements for the period from October 1992 to February 2005. It has a 7-day temporal resolution and a $1 / 3^{\circ} \times 1 / 3^{\circ}$ spatial resolution. For the detailed mapping method and data quality analysis, readers are referred to Le Traon et al. (1998) and Ducet et al. (2000).

To capture the large-scale SSH changes in the South Pacific Ocean, we start by conducting an empirical orthogonal function (EOF) analysis of the SSH anomaly data in the region of our interest: $10^{\circ}-60^{\circ} \mathrm{S}$. The first EOF mode explains $17.9 \%$ of the total variance, and its spatial pattern and weighting coefficient are shown in Fig. 2a. The weighting coefficient of the mode is dominated by a linearly increasing trend with embedded seasonal modulations. Given the dominance of the linear trend in this leading EOF mode, it is not surprising that its spatial pattern bears a close resemblance to the linear SSH trend pattern presented in Fig. 1. A closer look at the weighting coefficient hints that a reversal in sign of the trend occurred after 2001. This sign reversal is consistent with the findings by Roemmich et al. (2006) that after a decade of strengthening, the South Pacific subtropical gyre is experiencing a spindown in recent years.

The second EOF mode, shown in Fig. 2b, is dominated by the oppositely signed SSH anomalies in the western and eastern tropical Pacific band. For the period of our interest, this mode represents largely the occurrence of the 1997/98 El Niño event. Several studies in the past have described the SSH changes associated with this ENSO event in the equatorial Pacific Ocean (e.g., McPhaden 1999; Lagerloef et al. 1999), and we will restrict our discussions in this study to its effect on the regions south of $10^{\circ} \mathrm{S}$. Notice that while the linear SSH trend in the midlatitude South Pacific Ocean (Fig. 1) is represented effectively by the first SSH EOF mode, the low-frequency SSH variability in the tropical region $\left(10^{\circ}-25^{\circ} \mathrm{S}\right)$ is connected to signals represented in both the first and second EOF modes. 
(a) SSH EOF mode $1(17.9 \%$ of variance)
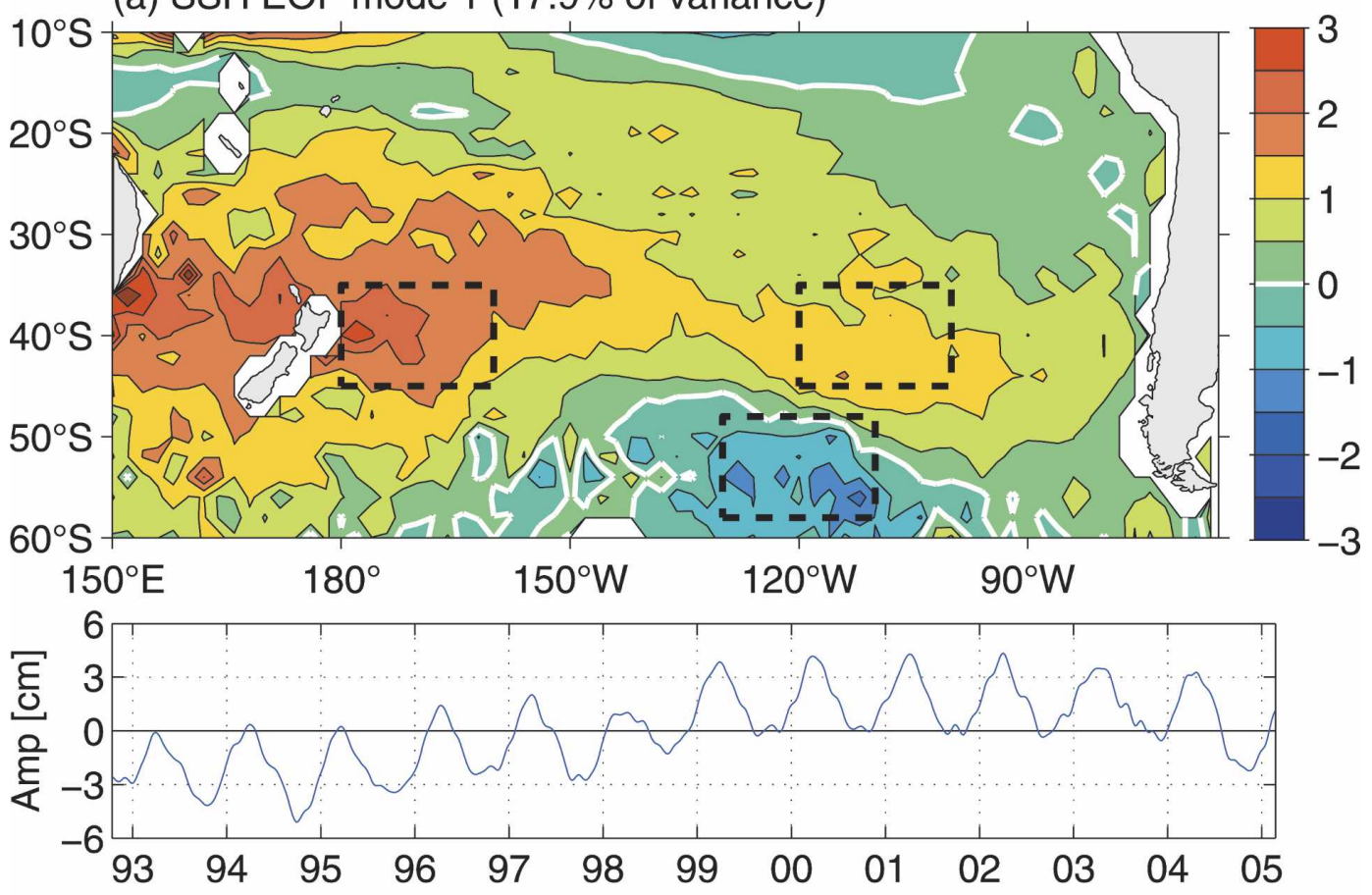

(b) SSH EOF mode 2 (11.2\% of variance)
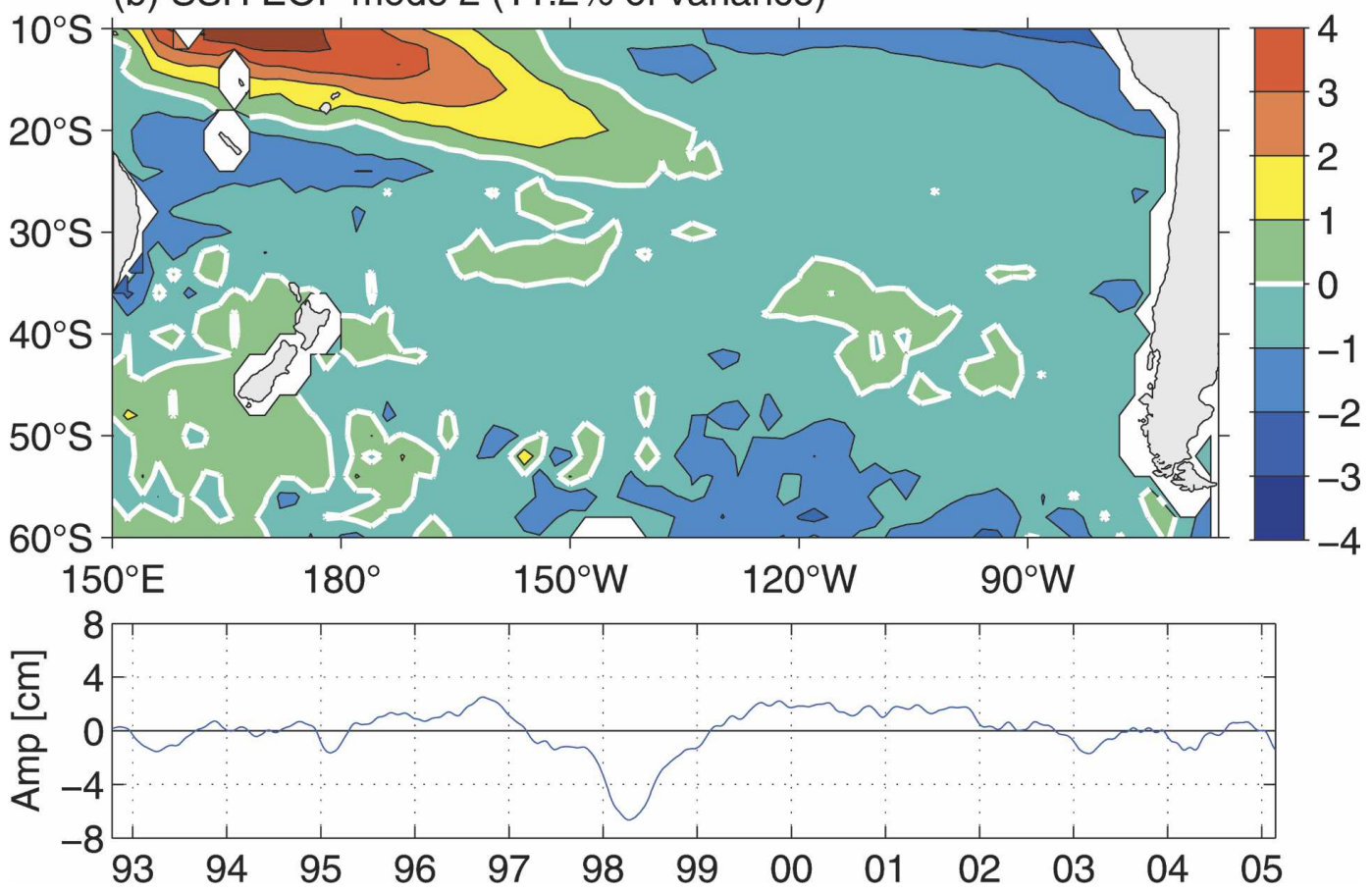

FIG. 2. (a) Spatial pattern and weighting function of the first EOF mode of the monthly SSH anomaly (SSHa) field. The spatial pattern is normalized such that it has an rms amplitude of unity over the region of interest. The dashed boxes indicate the three regions where detailed SSH comparisons are shown in Fig. 6 between the observations and the model hindcast. (b) Same as (a), but for the second EOF mode. 

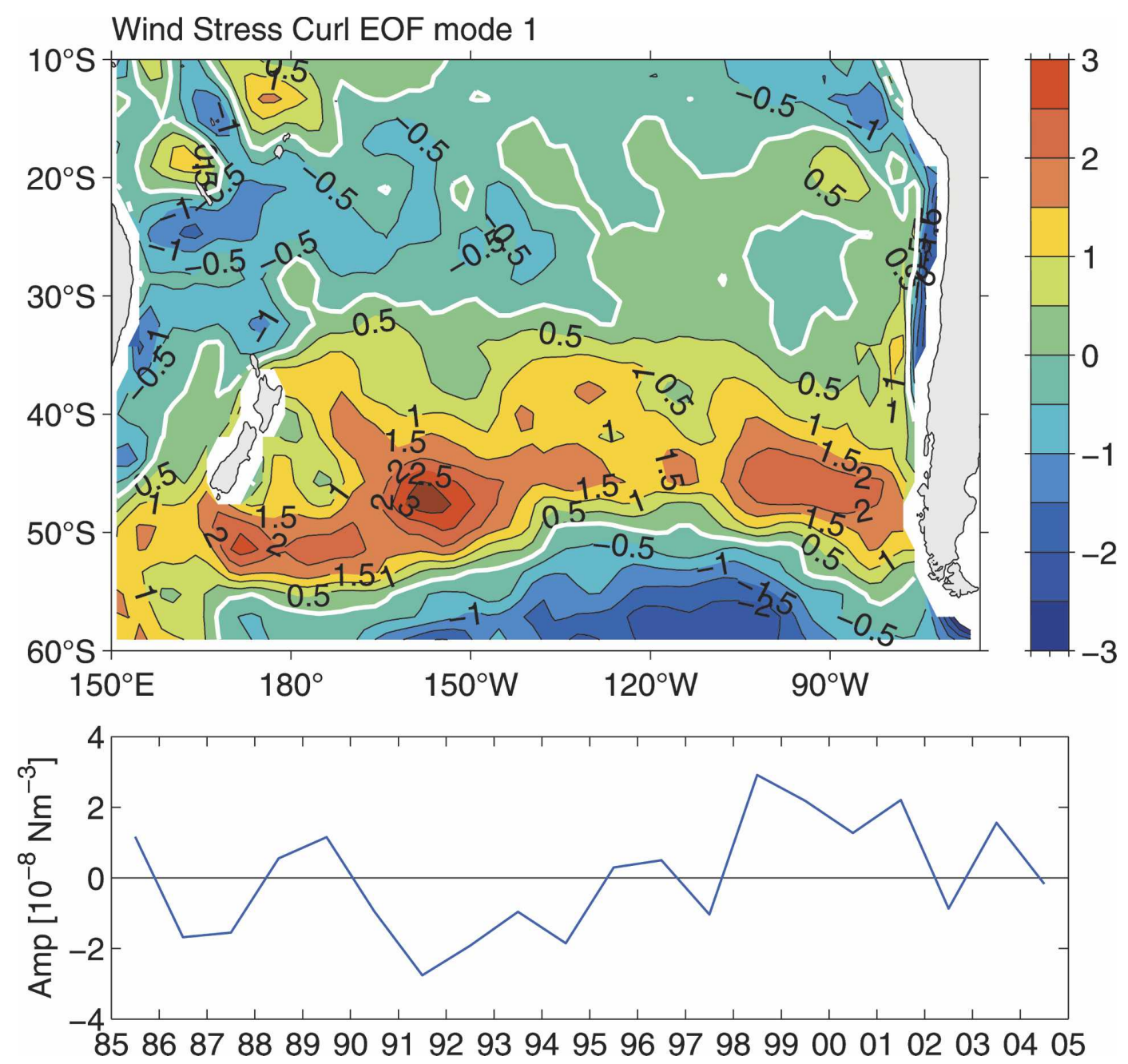

FIG. 3. Spatial pattern and weighting function of the first EOF mode of the yearly NCEP wind curl field. The mode explains $23.7 \%$ of the total variance. The spatial pattern is normalized such that it has an rms amplitude of unity over the region of interest.

\section{Large-scale SSH changes resulting from interior wind forcing}

To understand the large-scale SSH changes described in Fig. 2, we explore in this section the contributions from the interior surface wind forcing. Influence of the boundary forcing caused by SSH changes along the South American coast will be quantified in the next section.

\section{a. Interior wind forcing variability}

Figure 3 shows the first EOF mode of the annually averaged wind stress curl data over the South Pacific Ocean for the past two decades. The wind stress data are from the National Centers for Environmental Prediction-National Center for Atmospheric Research (NCEP-NCAR) reanalysis (hereinafter NCEP reanaly- sis; Kistler et al. 2001), and the annual mean time series is used for the EOF analysis because we are interested in the low-frequency variability. The first EOF mode explains $23.7 \%$ of the total variance, and the largeamplitude variability is mostly seen south of $30^{\circ} \mathrm{S}$ along the path of the Southern Hemisphere westerlies (e.g., Tomczak and Godfrey 1994). Relevant to the SSH signals in which we are interested, there exists a linear trend over much of the 1990s; the trend is positive, that is, there is increased Ekman pumping in the $30^{\circ}-50^{\circ} \mathrm{S}$ band, and it is negative (enhanced Ekman suction) in the band poleward of $55^{\circ} \mathrm{S}$. Notice that the linear trend seen in the 1990s reversed sign after 1999, and that this sign reversal in the wind stress curl field preceded the sign reversal in the SSH field, which occurred around 2001 (Fig. 2a), by about 2 yr.

Over much of the $10^{\circ}-30^{\circ} \mathrm{S}$ band, the wind stress curl 
variability is weak, signifying the steadiness of the Southern Hemisphere trade wind. In the Coral Sea, west of the date line, the wind variability becomes larger, reflecting the low-frequency changes in the monsoonal system in this region (e.g., Meehl 1987).

\section{b. The baroclinic Rossby wave model}

To relate these changes in the wind stress curl field to the observed SSH variability, we adopt in this study the $1 \frac{1}{2}$-layer reduced-gravity model that governs the baroclinic ocean response to surface wind forcing. This model has been used extensively in the past in investigating the SSH, or equivalently the upper ocean layer thickness, variability in the tropical Pacific Ocean (e.g., White 1977; Meyers 1979; Kessler 1990; Capotondi and Alexander 2001; Capotondi et al. 2003). More recently, it has been extended to studies of midlatitude SSH signals (e.g., Sturges and Hong 1995; Holbrook and Bindoff 1999; Schneider et al. 2002; Qiu 2002). The model dynamics are governed by the linear vorticity equation under the long-wave approximation

$$
\frac{\partial h}{\partial t}-c_{R} \frac{\partial h}{\partial x}=-\frac{g^{\prime} \operatorname{curl} \tau}{\rho_{o} g f}-\varepsilon h,
$$

where $h$ is the SSH anomaly of our interest, $c_{R}$ is the speed of the long baroclinic Rossby waves, $g^{\prime}$ is the reduced gravity, $\rho_{o}$ is the reference density, $f$ is the Coriolis parameter, $\boldsymbol{\tau}$ is the wind stress anomaly vector, and $\varepsilon$ is the Newtonian dissipation rate. Integrating Eq. (1) from the eastern boundary $\left(x_{e}\right)$ along the baroclinic Rossby wave characteristic leads to

$$
\begin{aligned}
h_{I}(x, y, t)= & \frac{g^{\prime}}{\rho_{o} g f c_{R}} \int_{x_{e}}^{x} \operatorname{curl} \tau\left(x^{\prime}, y, t+\frac{x-x^{\prime}}{c_{R}}\right) \\
& \times \exp \left[\frac{\varepsilon_{I}}{c_{R}}\left(x-x^{\prime}\right)\right] d x^{\prime} .
\end{aligned}
$$

In Eq. (2), we have ignored the contribution from the SSH signals along the eastern boundary, and $h_{I}$ here signifies the SSH changes induced by the interior wind forcing only. Effects of the boundary forcing will be quantified in section 4.

To evaluate $h_{I}$, we use the monthly wind stress data (with the long-term mean removed) from the NCEP reanalysis from 1948. The horizontal resolution of the NCEP data is $1.904^{\circ}$ latitude $\times 1.825^{\circ}$ longitude. For the long baroclinic Rossby wave speed $c_{R}$, we use the value derived by Chelton et al. (1998) with a latitude-dependent amplification factor $\alpha(y)=1.0+$ $0.025 \times\left(y-10^{\circ} \mathrm{S}\right)$. It is well established now that the observed $c_{R}$ exceeds the value determined by the standard long Rossby wave theory (Chelton and Schlax

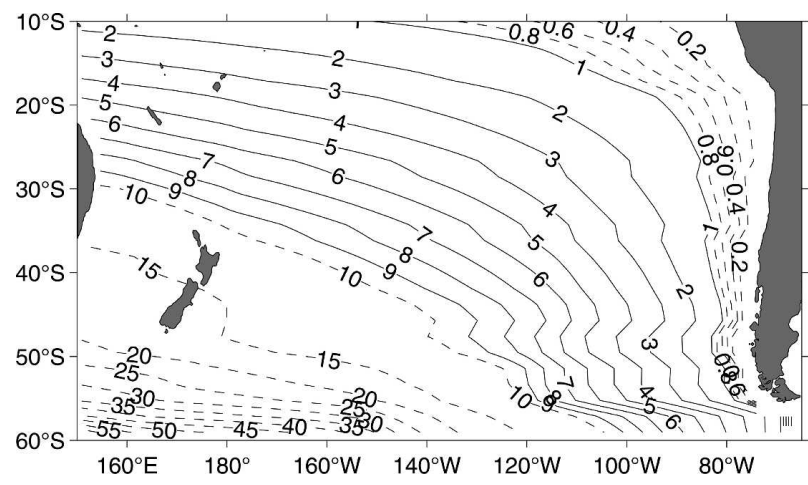

FIG. 4. Time required for the long baroclinic Rossby waves to traverse the South Pacific Ocean. For each latitude, the value plotted at each longitude is the wave transit time from the eastern boundary to that longitude (yr). The Rossby wave speed is based on Chelton et al. (1998), with an amplification factor of $1.0+$ $0.025 \times\left(y-10^{\circ} \mathrm{S}\right)$. Notice that the contour intervals are $0.2 \mathrm{yr}$ in the northeast, $1 \mathrm{yr}$ in the central, and $5 \mathrm{yr}$ in the southwest part of the basin.

1996); the factor $\alpha(y)$ accounts for this discrepancy and is based on the altimetrically derived ratios found in the South Pacific Ocean (see Fig. 14 in Fu and Chelton 2001). Figure 4 shows the time required for the baroclinic Rossby waves to traverse the South Pacific basin from the eastern boundary based on the "adjusted" $c_{R}$ values. Typical transit times range from one to several years in the tropical band and from one to several decades in the midlatitude band.

Along the midlatitude band where the transit time is long, the wind-forced SSH signals tend to dissipate due to eddy mixing as they propagate westward. This effect is parameterized in Eq. (1) by the Newtonian dissipation term. Following the studies of the midlatitude North Pacific by Schneider et al. (2002) and Qiu (2002), $\varepsilon_{I}=(6 \mathrm{yr})^{-1}$ is adopted in this study as the dissipation coefficient. Notice that choosing an $\varepsilon_{I}$ value in the range from $(3 \mathrm{yr})^{-1}$ to $(10 \mathrm{yr})^{-1}$ will not alter the predictive skill of Eq. (2) significantly. Readers interested in the details of $\varepsilon_{I}$ dependency are referred to Fig. 9a in Qiu (2002). The $g^{\prime}$ value represents the strength of stratification in the $1 \frac{1}{2}$-layer reduced-gravity model. While it does not influence the pattern of the $h_{I}$ field, its value does control the magnitude of the solution. In this study, we assume $g^{\prime}$ is a function of latitude. (This assumption is reasonable because stratification is largely determined by air-sea buoyancy flux forcing, which is a function of latitude.) For each latitudinal band, $g^{\prime}$ is first evaluated by assuming the modeled $h_{I}$ field has the same variance as the observed SSH field (see the plus marks in Fig. 5). The final value for $g^{\prime}(y)$ is obtained by fitting these initial $g^{\prime}$ values to a $y$-dependent parabolic curve (the thick curve in Fig. 5). 


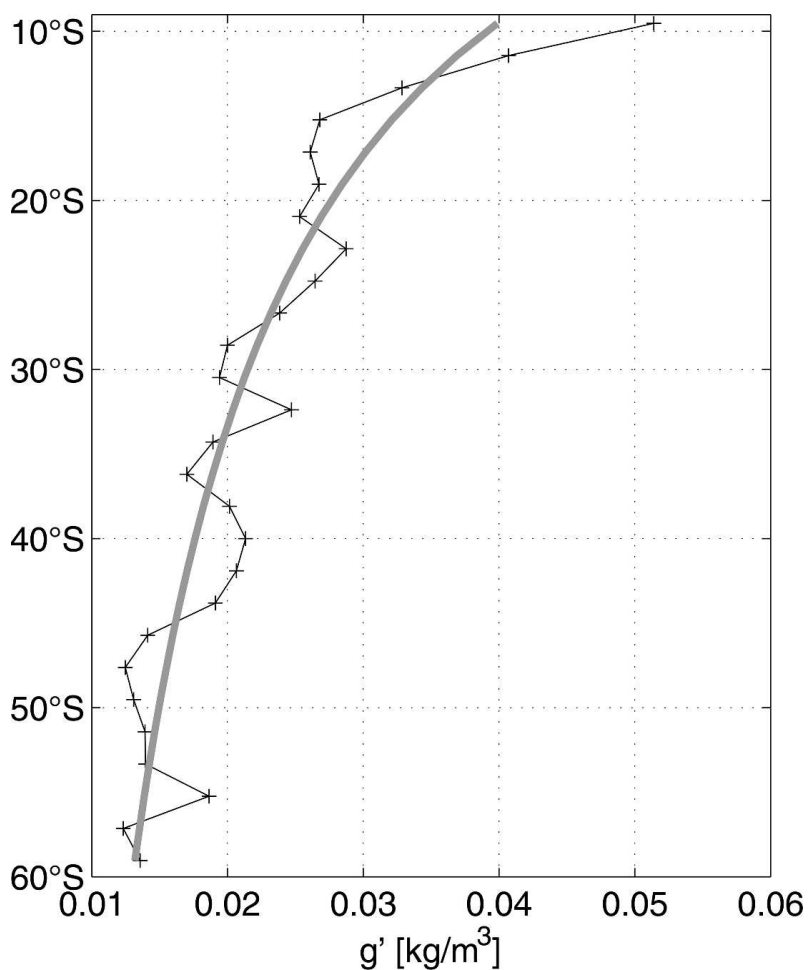

FIG. 5. Reduced-gravity value $g^{\prime}$ as a function of latitude. Crosses denote the values obtained by requiring the wind-forced interior SSH solution [i.e., Eq. (2)] to have the same variance as the observed SSH data within individual latitudinal bands. The thick gray line denotes the best fit by a $y$-dependent parabolic curve.

\section{c. The model results}

To evaluate the performance of the model, we examine first the SSH time series in three midlatitude $10^{\circ}$ latitude $\times 20^{\circ}$ longitude boxes in which the observed SSH signals have distinct characteristics based on the EOF analysis (see the dashed boxes in Fig. 2a). Model results in the tropical band will be considered in the next section in connection with the boundary forcing. The first box is centered at $40^{\circ} \mathrm{S}, 170^{\circ} \mathrm{W}$ east of New Zealand where the observed SSH data have the largest increasing trend. The averaged SSH signals in this box very much resemble the temporal coefficient of the first SSH EOF mode (cf. Fig. 2a). In Fig. 6a, the thin dark line shows the SSH time series based on the original weekly dataset and the thick dashed line shows the annually averaged SSH time series. The second box is centered at $53^{\circ} \mathrm{S}, 120^{\circ} \mathrm{W}$ where the observed SSH signals have a contrasting decreasing trend. Figure $6 \mathrm{~b}$ indicates that this decreasing trend appeared mostly prior to 1999 , and the trend reversed sign after 2000. The third box has its center at $40^{\circ} \mathrm{S}, 110^{\circ} \mathrm{W}$. It is located in the eastern midlatitude South Pacific where there
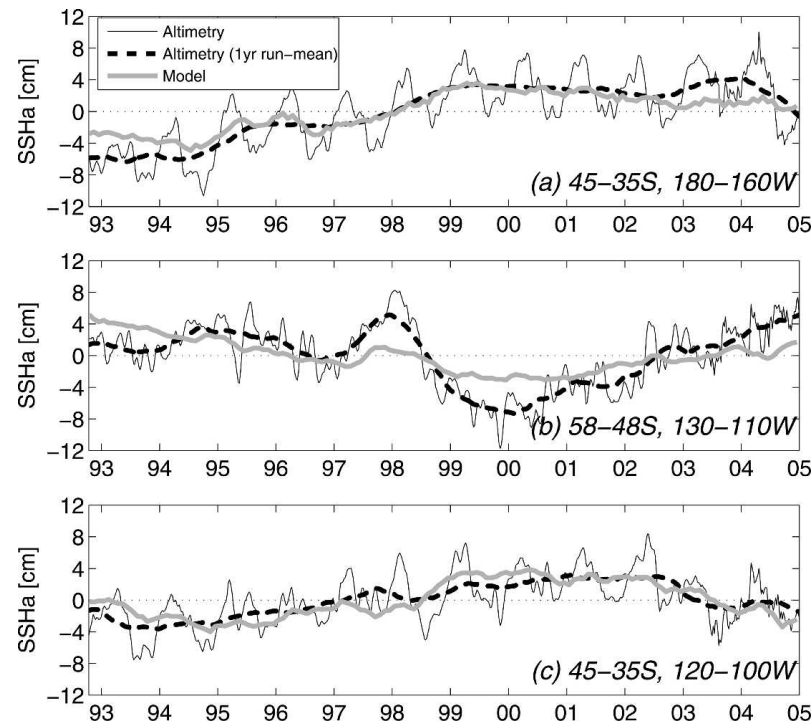

FIG. 6. Observed (black lines) vs modeled (thick gray line) SSHa in the three representative regions of the South Pacific Ocean: (a) $35^{\circ}-45^{\circ} \mathrm{S}, 180^{\circ}-160^{\circ} \mathrm{W}$; (b) $48^{\circ}-58^{\circ} \mathrm{S}, 130^{\circ}-110^{\circ} \mathrm{W}$; and (c) $35^{\circ}-45^{\circ} \mathrm{S}, 120^{\circ}-100^{\circ} \mathrm{W}$. For the observed signals, the thin black lines indicate the weekly time series and the thick dashed lines the annually averaged time series.

is a local maximum in the increasing SSH trend (see Fig. 2a).

The modeled $h_{I}$ time series averaged in these three boxes are shown in Fig. 6 by thick gray lines. For box 1 off of New Zealand (Fig. 6a), the observed increasing trend is reproduced fairly well by the baroclinic Rossby wave model. With the modeled SSH anomalies in 1993/ 94 being less negative than the observations, the modeled linear trend $\left(4.9 \mathrm{~mm} \mathrm{yr}^{-1}\right)$ is weaker than the observed trend $\left(8.1 \mathrm{~mm} \mathrm{yr}^{-1}\right)$. For box 2, the observed decreasing SSH trend of 1993-99 is captured reasonably well in the model. Although the model has the correct sign, it is less successful in simulating the magnitude of the increasing trend observed after 2000 (Fig. 6b). By contrast, the model is very successful in reproducing the decadal SSH changes observed in box 3; this includes the initial increasing trend in 1993-2001 and the subsequent decreasing trend after 2000. The overall linear trend shown in Fig. $6 \mathrm{c}$ is $3.5 \mathrm{~mm} \mathrm{yr}^{-1}$ from the observations and $3.4 \mathrm{~mm} \mathrm{yr}^{-1}$ from the model.

To gain a better appreciation of the temporal and spatial structures of the modeled and observed SSH changes, we compare in Fig. 7 the time-longitude diagrams of the observed and modeled interannual SSH anomalies along $40^{\circ} \mathrm{S}$ between New Zealand and the Chilean coast. While there are detailed differences (e.g., the lack of large negative SSH anomalies in 1993/ 94 and large positive SSH anomalies in 2003/04 near $170^{\circ} \mathrm{W}$ in the model), the overall correspondence be- 
(a) Observed $\mathrm{SSHa}$

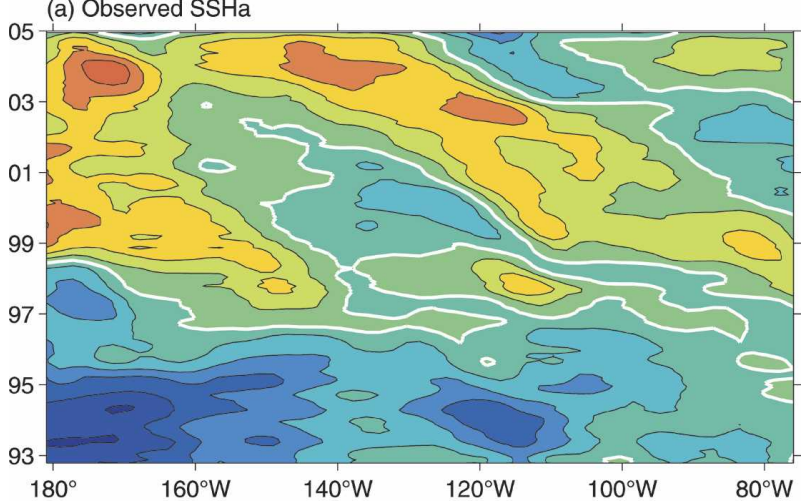

(b) Modeled SSHa

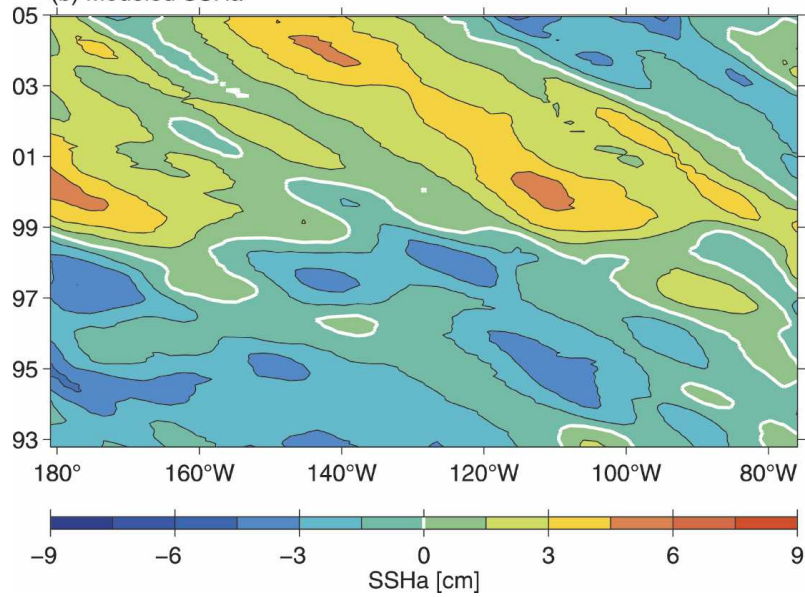

FIG. 7. (a) Time-longitude plot of the interannual SSHa observed by satellite altimeters along $40^{\circ} \mathrm{S}$ from New Zealand to the Chilean coast. (b) Same as (a), except the result is based on the wind-forced baroclinic Rossby wave model [Eq. (2)].

tween the two patterns is very favorable. Both patterns show general negative SSH anomalies prior to 1997 and positive anomalies thereafter. Large-amplitude positive SSH anomalies are seen both in the model and in the observations to initiate around $150^{\circ}$ and $110^{\circ} \mathrm{W}$, respectively, and both of these anomalies in the model and the observations move westward subsequently. In the eastern basin, both the model and the observations reveal negative SSH anomalies forming near the Chilean coast in about 2000 and propagating westward to reach the $110^{\circ}-120^{\circ} \mathrm{W}$ region in 2004 . These propagating negative SSH anomalies are responsible for the reversal (from increasing to decreasing) in the SSH trend seen in Fig. 6c.

\section{d. Rossby wave versus Ekman dynamics}

Several past investigations of the low-frequency SSH changes in the midlatitude North Pacific Ocean have suggested the relevance of Ekman dynamics (e.g.,

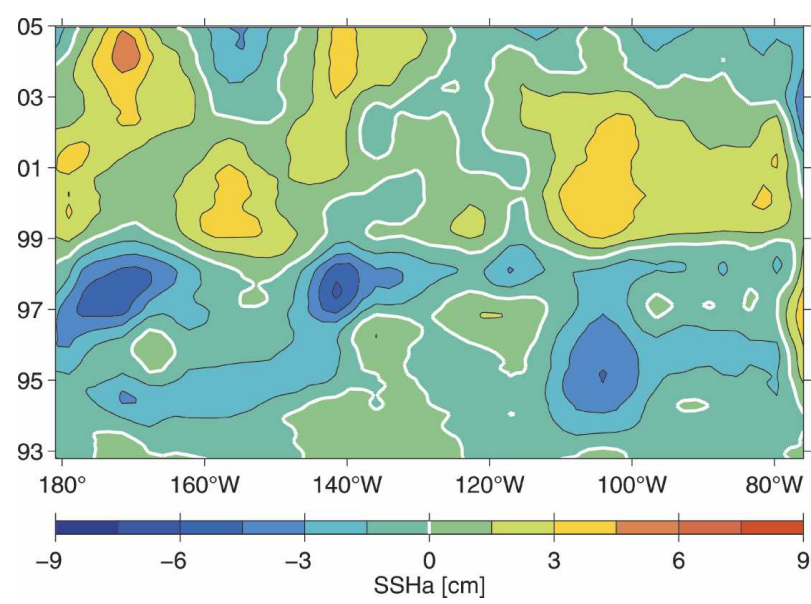

FIG. 8. Time-longitude plot of the interannual SSHa along $40^{\circ} \mathrm{S}$ from New Zealand to the Chilean coast. Based on the model with Ekman dynamics [Eq. (4)].

Cummins and Lagerloef 2004; Capotondi et al. 2005). In this case, instead of the baroclinic Rossby wave [Eq. (1)], the rate of SSH change is governed by convergence/divergence of the anomalous Ekman fluxes,

$$
\frac{\partial h_{\mathrm{Ek}}}{\partial t}=-\frac{g^{\prime} \operatorname{curl} \tau}{\rho_{o} g f}-\varepsilon_{I} h_{\mathrm{Ek}},
$$

with the solution

$$
h_{\mathrm{EK}}(x, y, t)=-\frac{g^{\prime}}{\rho_{o g f}} \int_{t} \operatorname{curl} \tau\left(x, y, t^{\prime}\right) \exp \left[-\varepsilon_{I}\left(t-t^{\prime}\right)\right] d t^{\prime} .
$$

To test this hypothesis, we present in Fig. 8 the same time-longitude diagram as in Fig. 7b, except that the model solution in this case is based on Eq. (4) using the monthly wind stress curl anomaly data from the NCEP reanalysis. ${ }^{1}$ While the $h_{\mathrm{Ek}}$ solution shows a generally increasing SSH trend over the past decade, its ability to hindcast the observed SSH pattern in the midlatitude South Pacific Ocean is much inferior to the baroclinic Rossby wave solution: the linear correlation between Figs. 8 and 7 a has a coefficient of 0.45 , as compared with 0.73 between Figs. $7 \mathrm{~b}$ and $7 \mathrm{a}$. Also important, the Ekman solution misses the westward-propagating signals present in the observations. Indeed, the lack of these propagating signals makes the Ekman solution unable to capture either the negative SSH anoma-

\footnotetext{
${ }^{1}$ The initial condition for the solution in Eq. (4) can be set arbitrarily to zero. This arbitrary constant is determined by requiring $h_{\mathrm{EK}}$ to have a zero temporal mean.
} 
lies or the decreasing SSH trend that appear in the eastern midlatitude South Pacific in recent years (recall Fig. 6c).

In concluding this section, we note that while the baroclinic Rossby wave dynamics provide a useful basis for understanding the midlatitude SSH variability on the interannual-to-decadal time scales, it fails to explain the SSH signals on the annual and shorter time scales (Fig. 6). On the annual time scale, the observed SSH changes have been shown by Stammer (1997) and Vivier et al. (1999) to result from a combination of the seasonal surface buoyancy forcing and the barotropic Sverdrup response to the seasonal surface wind stress curl forcing. On the shorter intraseasonal time scales, much of the observed SSH variability in the midlatitude South Pacific can be shown to be barotropic responses induced by synoptic-scale atmospheric disturbances. Readers interested in this topic are referred to $\mathrm{Fu}$ (2003) and the references therein.

\section{Effects of the eastern boundary forcing}

In Fig. 9a, we plot the distribution of the linear correlation coefficient between the SSH time series from the wind-driven baroclinic Rossby wave model [i.e., Eq. (2)] and the observations. In the midlatitude South Pacific, the wind-driven model simulates the observed SSH changes generally well, with the linear correlation coefficient in the broad interior regions exceeding 0.6. Because the large-scale SSH signals here are dominated by the 1990s' trends and their recent reversals (recall Fig. 6), caution is, however, needed in ascertaining the significance of these coefficient values. The correlation between the model and the observations drops rather rapidly toward the southern edge where mesoscale eddy variability associated with the Antarctic Circumpolar Current becomes dominant. Another zonal band where the wind-driven Rossby wave dynamics poorly explain the observed SSH signals is along $25^{\circ}-30^{\circ} \mathrm{S}$. This band, as investigated recently by Qiu and Chen (2004) and Bowen et al. (2005), corresponds to where the South Tropical Countercurrent (STCC) and the East Australian Current (EAC) are located. With the regionally enhanced eddy variability associated with the instability of these current systems (see, e.g., Fig. 1 in Qiu and Chen 2004), the low correlation between the observed SSH signals and those forced by the largescale surface wind stress curl is expected. A third area, where the correlation coefficient is low on a broad scale in Fig. 9a, is in the low-latitude eastern South Pacific and along the South American coast. It is on these latter two regions that we will be focusing in this section.
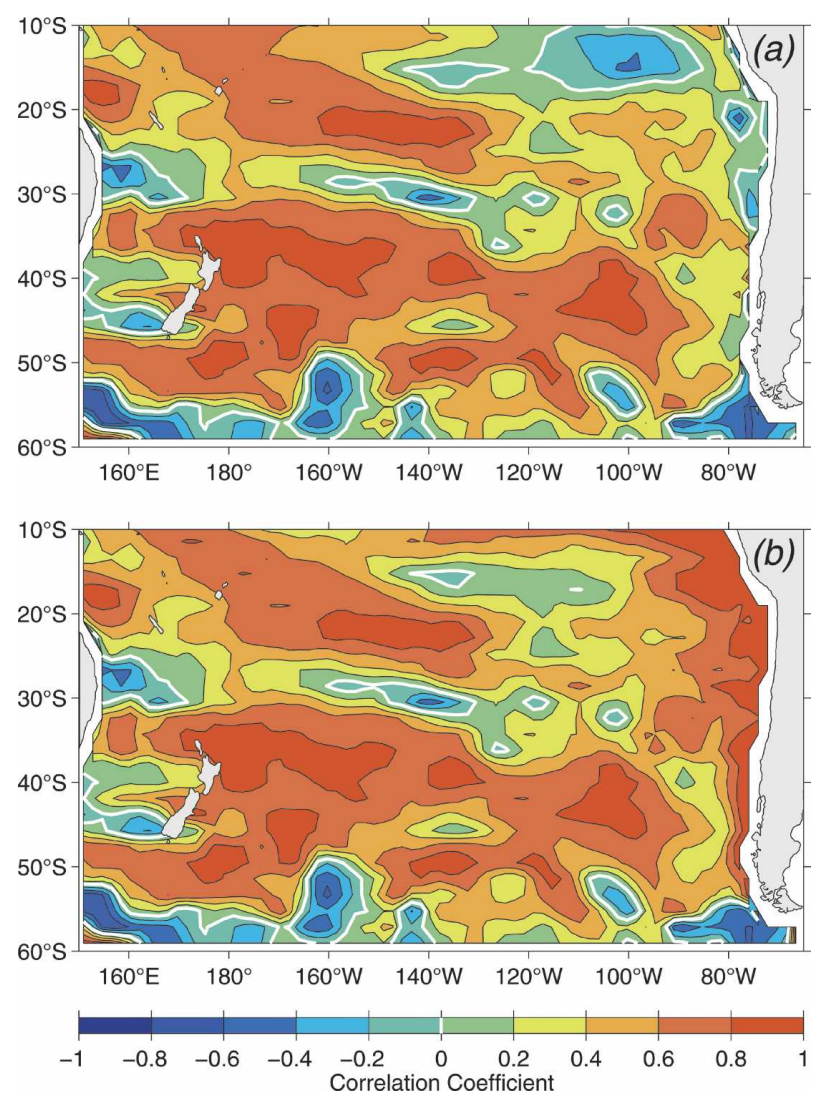

FIG. 9. (a) Map of linear correlation coefficient between yearly averaged SSHa from the observations and the wind-driven model [Eq. (2)]. (b) Same as (a), except the model is both wind and boundary driven [i.e., Eq. (5)].

When the SSH along the eastern boundary $\left(x=x_{e}\right)$ fluctuates with time, the general solution to Eq. (1) becomes

$h(x, y, t)=h_{I}(x, y, t)+h\left(x_{e}, y, t+\frac{x-x_{e}}{c_{R}}\right) \exp \left[\frac{\varepsilon_{B}}{c_{R}}\left(x-x_{e}\right)\right]$

where $\varepsilon_{B}$ denotes the Newtonian dissipation rate associated with the boundary-forced signals and $h_{I}$ is given by Eq. (2). Notice that $\varepsilon_{B}$ does not need to have the same value as that for the interior wind-forced signals $\varepsilon_{I}$. Along the eastern boundary, additional dissipation can occur because of topographic scattering and the vertical propagation of wave energy into the subthermocline ocean (Kessler and McCreary 1993). To evaluate the influence of the boundary forcing [i.e., the last term in Eq. (5)], we adopt the approach of Fu and Qiu (2002) by regarding the monthly observed SSH values next to the coast as $h\left(x_{e}, y, t\right)$. In their study of the eastern South Pacific, Vega et al. (2003) adopted a dy- 

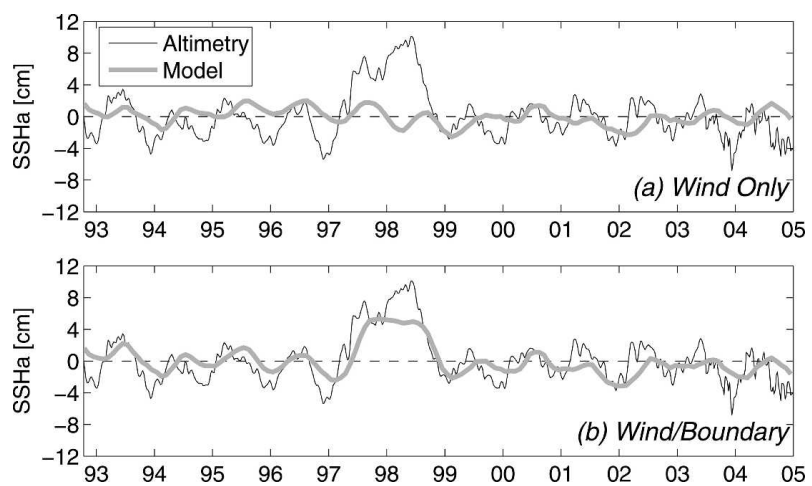

FIG. 10. (a) Observed (thin black line) vs modeled (thick gray line) SSHa in the eastern tropical South Pacific region offshore of Peru: $10^{\circ}-20^{\circ} \mathrm{S}, 100^{\circ}-80^{\circ} \mathrm{W}$. The model is driven by the interior wind forcing only. (b) Same as (a), except the model is driven by both the interior wind and boundary forcing.

namic model similar to Eq. (5) and estimated the Newtonian dissipation rate $\varepsilon_{B}$ by minimizing the difference between the modeled and observed SSH variance in the region of $10^{\circ}-40^{\circ} \mathrm{S}$ and $120^{\circ}-70^{\circ} \mathrm{W}$. Following their analysis, we choose $\varepsilon_{B}=(300 \text { days })^{-1}$.

Figure $9 \mathrm{~b}$ shows the distribution of the linear correlation coefficient between the SSH time series from the observations and the model when the boundary-forced solution is included. Compared to Fig. 9a, significant improvement in the model's hindcast skill is seen in the eastern tropical South Pacific and along the South American coast. This result is consistent with the findings by Vega et al. (2003), who stressed the importance of the boundary forcing for the observed SSH signals in the eastern tropical South Pacific. It is worth emphasizing that the influence of the boundary forcing has an $e$-folding time scale of $\varepsilon_{B}^{-1}=300$ days. From Fig. 4 , this implies that the length scale of the boundary influence narrows rather rapidly as a function of latitude. At $40^{\circ} \mathrm{S}$, for example, the $e$-folding length scale for the boundary-forced solution is only $\sim 8^{\circ}$ wide. A look at Figs. $9 \mathrm{a}$ and $9 \mathrm{~b}$ clearly reflects this point, namely, adding the boundary forcing does not improve the SSH hindcast along $40^{\circ} \mathrm{S}$ beyond the $8^{\circ}$ band of the South American coast.

To examine the boundary-forced SSH signals in the eastern tropical South Pacific Ocean in more detail, we plot in Fig. 10 the observed and modeled SSH time series in the $10^{\circ}$ latitude $\times 20^{\circ}$ longitude box centered at $15^{\circ} \mathrm{S}$ and $90^{\circ} \mathrm{W}$. It is interesting to note that the $h_{I}$ solution (thick gray line in Fig. 10a) completely misses the 1997/98 El Niño-related positive SSH anomaly signal. In other words, there is little surface wind variability in this eastern tropical South Pacific region that is connected to the 1997/98 ENSO event. ${ }^{2}$ When the boundary forcing is included (Fig. 10b), much of the observed SSH anomalies of 1997/98 are captured by the model, indicating that the ENSO-related SSH signal in this box offshore of Peru is driven by the coastal SSH anomalies that are generated at the equator and propagate poleward through the coastal waveguide (e.g., Clarke and Van Gorde 1994; Pizarro et al. 2001; Strub and James 2002).

It is important to emphasize that unlike the midlatitude region considered in the previous section, the baroclinic Rossby wave dynamics are important for the observed annual cycle of the SSH signal. For the box considered in Fig. $10\left(10^{\circ}-20^{\circ} \mathrm{S}, 100^{\circ}-80^{\circ} \mathrm{W}\right)$, the windforced solution explains approximately two-thirds of the observed annual SSH signal. The remaining onethird of the signal originates along the Peruvian coast, where seasonal intensification/relaxation of the southeast trade wind induces an annual SSH change as a result of modulating coastal upwelling (Strub et al. 1998).

We note that the $10^{\circ}-20^{\circ} \mathrm{S}$ band offshore of the Peruvian coast is one of the regions where the linear $\mathrm{SSH}$ trend over the past $12 \mathrm{yr}$ is observed to be negative (see Fig. 1). Although weak in its rate $\left(0.84 \mathrm{~mm} \mathrm{yr}^{-1}\right)$, this observed decreasing trend can be visually discerned in the thin lines shown in Fig. 10. A similar decreasing trend, with a rate of $1.52 \mathrm{~mm} \mathrm{yr}^{-1}$, is found in the model solution that contains both the interior and boundary forcing (the thick line in Fig. 10b). To this modeled decreasing rate, the interior wind and boundary solutions contribute $55 \%$ and $45 \%$, respectively.

\section{Discussion and conclusions}

Using the multisatellite altimetry measurements of the past $12 \mathrm{yr}$, we examined the low-frequency sea surface height variability in the extraequatorial South $\mathrm{Pa}$ cific Ocean. Particular attention was paid to the geographically dependent SSH changes on decadal time scales. In addition to the descriptions of these changes, a 11/2-layer reduced-gravity model was adopted to provide a dynamic framework that helps our understanding of the observed signals. The model includes the first-mode baroclinic Rossby wave dynamics and the responses forced by SSH changes along the model's

\footnotetext{
${ }^{2}$ This notion is consistent with the studies of teleconnection pattern of the South Pacific atmosphere by Mo and Ghil (1987) and Karoly (1989), who showed that the so-called Pacific-South American (PSA) teleconnection pattern has little ENSO-related surface wind variance over the eastern tropical South Pacific Ocean.
} 


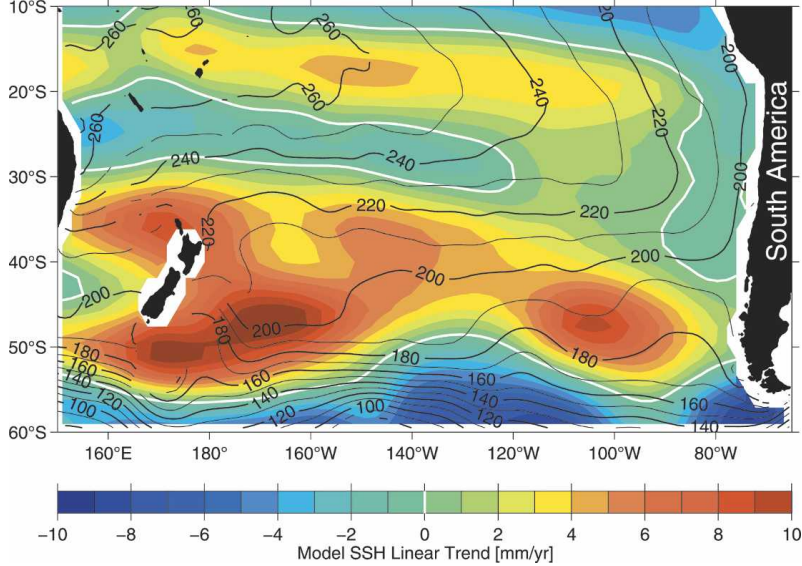

FIG. 11. Linear trend in the modeled SSH field from October 1992 to December 2004. The model is driven by both the interior wind and boundary forcing. Black contours denote the climatological sea surface dynamic height field (0-2000 dbar) from WOA01 (Conkright et al. 2002) (cm).

eastern boundary. Though simple in its formulation, we found that the model contains the essential dynamics underlying many of the observed low-frequency SSH signals.

In the midlatitude region south of $30^{\circ} \mathrm{S}$, the largescale SSH signals in the South Pacific Ocean over the past $12 \mathrm{yr}$ are dominated by an increasing trend in both the western basin around New Zealand and the eastern basin centered around $45^{\circ} \mathrm{S}, 105^{\circ} \mathrm{W}$. In contrast, a decreasing SSH trend appears in the central South Pacific Ocean poleward of $50^{\circ} \mathrm{S}$. These three major features are captured well by the baroclinic Rossby wave model (Fig. 11), indicating the importance of the large-scale surface wind forcing in generating the spatially nonuniform SSH variations. It is worth emphasizing that both the increasing SSH trend seen in the midlatitude band of $30^{\circ}-50^{\circ} \mathrm{S}$ and the decreasing SSH trend poleward of $50^{\circ} \mathrm{S}$ have reversed in recent years. For the midlatitude South Pacific Ocean, the effect of boundary forcing associated with the time-varying SSH signals along the South American coast is spatially confined and, therefore, unimportant for the large-scale SSH changes away from the coast.

In contrast to the baroclinic Rossby wave dynamics, we have also in this study examined the Ekman dynamics in which the SSH changes are determined by the local wind stress curl forcing. Figure 12 shows the map of the linear correlation coefficient between the SSH time series from the Ekman model [i.e., Eq. (4)] and the observations. Compared to the same map between the Rossby wave model and the observations (Fig. 9a), the overall hindcast skill by the Ekman model is much lower. Even in localized areas where the linear corre-

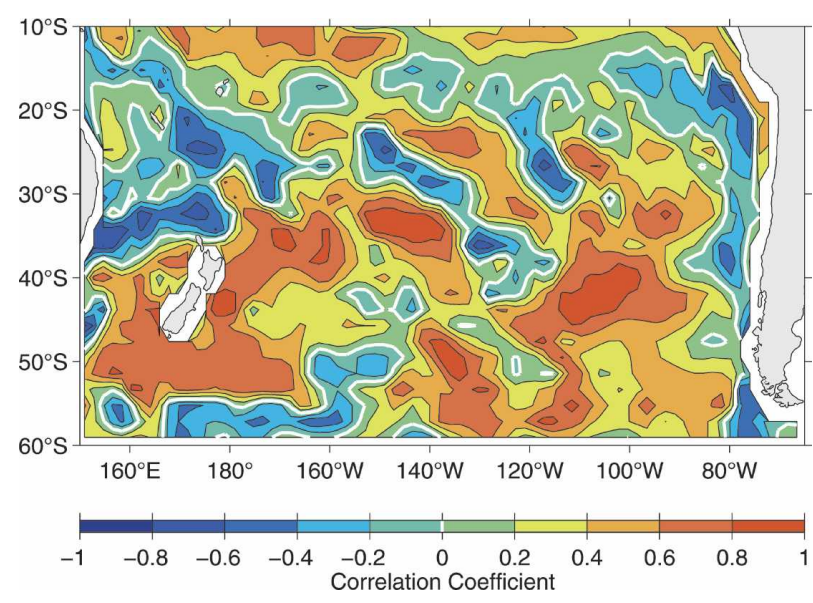

FIG. 12. Map of linear correlation coefficient between yearly averaged SSHa from the observations and the Ekman model [Eq. (4)].

lation coefficients in Figs. 12 and 9a appear comparable, for example, around $40^{\circ} \mathrm{S}, 105^{\circ} \mathrm{W}$, the in-depth comparisons presented in Figs. 7 and 8 reveal that when the surrounding SSH signals are taken into account, the Rossby wave model offers a better explanation for the underlying dynamics of the observed SSH signals than the Ekman model does. Making the distinction between the Rossby wave dynamics and the Ekman dynamics is important because the former dynamics imply the impact of the interior wind forcing upon the East Australian Current and the potential for predictive skill in the western South Pacific basin, whereas the latter does not. Indeed, a recent study by Cai (2006) has observed the strengthening of the EAC as a result of the intensification in the interior wind stress curl field in the midlatitude South Pacific Ocean.

While unimportant in the midlatitude ocean, the boundary forcing is crucial for the low-frequency SSH signals in the eastern tropical South Pacific. In the band of $10^{\circ}-20^{\circ} \mathrm{S}$ off of Peru, the boundary-forced SSH signal explains $\sim 1 / 3$ of the observed annual SSH variability and $\sim 54 \%$ of the observed decreasing SSH trend. For the $1997 / 98$ El Niño-related interannual variability, the observed SSH anomalies are found to be generated entirely by the boundary SSH forcing along the South American coast. The dominance of this boundaryforced solution is related to the fact that the wind stress curl field in the eastern tropical South Pacific lacks any El Niño-related anomalies in 1997/98.

While providing a useful dynamic framework for many of the observed SSH signals, the baroclinic Rossby wave model is less successful in regions where there is enhanced mesoscale eddy variability (e.g., along the $20^{\circ}-30^{\circ} \mathrm{S}$ band and along part of the Antarctic 
Circumpolar Current where the low-frequency wind forcing is relatively weak). Processes that would allow mesoscale eddy variability to cause regional SSH changes on a longer time scale need to be explored in future studies. Another area where the model is less effective in explaining the observed SSH trend is in the western tropical South Pacific. While the observed SSH data reveal a spatially coherent increasing trend, the model result suggested a rather weak trend (Fig. 11). This discrepancy could be due to the fact that the observed SSH signals in this region are influenced by the western Pacific warm pool, whose interannual-todecadal movement is not governed solely by baroclinic Rossby wave dynamics. To fully understand the SSH changes in the western tropical South Pacific, an investigation based on more complete dynamics in the lowlatitude Pacific Ocean basin is called for.

Acknowledgments. This study benefited from fruitful discussions with Wenju Cai, Ted Durland, and Niklas Schneider. Dean Roemmich generously shared an early manuscript of his study with colleagues of the decadal South Pacific circulation changes. Detailed comments made by the anonymous reviewers helped to improve an early version of the manuscript. The surface wind stress data were generously provided by the National Centers for Environmental Prediction and the merged T/P, Jason-1, and ERS-1/2 altimeter data were provided by the CLS Space Oceanography Division as part of the Environment and Climate EU ENACT project. This study was supported by NASA through Contracts 1207881 and 1228847.

\section{REFERENCES}

Bowen, M. M., J. L. Wilkin, and W. J. Emery, 2005: Variability and forcing of the East Australian Current. J. Geophys. Res., 110, C03019, doi:10.1029/2004JC002533.

Cabanes, C., A. Cazenave, and C. Le Provost, 2001: Sea level rise during past 40 years determined from satellite and in situ observations. Science, 294, 840-842.

Cai, W., 2006: Antarctic ozone depletion causes an intensification of the Southern Ocean super-gyre circulation. Geophys. Res. Lett., 33, L03712, doi:10.1029/2005GL024911.

Capotondi, A., and M. A. Alexander, 2001: Rossby waves in the tropical North Pacific and their role in decadal thermocline variability. J. Phys. Oceanogr., 31, 3496-3515.

— - _ and C. Deser, 2003: Why are there Rossby wave maxima in the Pacific at $10^{\circ} \mathrm{S}$ and $13^{\circ} \mathrm{N}$ ? J. Phys. Oceanogr., 33, 1549-1563.

$\longrightarrow,-,-$, and A. J. Miller, 2005: Low-frequency pycnocline variability in the Northeast Pacific. J. Phys. Oceanogr., 35, 1403-1420.

Cazenave, A., and R. S. Nerem, 2004: Present-day sea level change: Observations and causes. Rev. Geophys., 42, RG3001, doi:10.1029/2003RG000139.
Chelton, D. B., and M. G. Schlax, 1996: Global observations of oceanic Rossby waves. Science, 272, 234-238.

, R. A. de Szoeke, M. G. Schlax, K. E. Naggar, and N. Siwertz, 1998: Geographical variability of the first baroclinic Rossby radius of deformation. J. Phys. Oceanogr., 28, 433-460.

Church, A. J., N. J. White, R. Coleman, K. Lambeck, and J. X. Mitrovica, 2004: Estimates of the regional distribution of sea level rise over the 1950-2000 period. J. Climate, 17, 26092625.

Clarke, A., and S. Van Gorde, 1994: On ENSO coastal currents and sea level. J. Phys. Oceanogr., 24, 661-680.

Conkright, M. E., R. A. Locarnini, H. E. Garcia, T. D. O'Brien, T. P. Boyer, C. Stephens, and J. I. Antonov, 2002: World Ocean Atlas 2001: Objective Analyses, Data Statistics, and Figures, CD-ROM Documentation. National Oceanographic Data Center, $17 \mathrm{pp}$.

Cummins, P. F., and G. G. E. Lagerloef, 2004: Wind-driven interannual variability over the northeast Pacific Ocean. Deep-Sea Res. I, 51, 2105-2121.

Ducet, N., P.-Y. Le Traon, and G. Reverdin, 2000: Global highresolution mapping of ocean circulation from TOPEX/ Poseidon and ERS-1 and -2. J. Geophys. Res., 105, $19477-$ 19498.

Fu, L.-L., 2003: Wind-driven intraseasonal sea level variability of the extratropical oceans. J. Phys. Oceanogr., 33, 436-449.

— ellite Altimetry and Earth Sciences, L.-L. Fu and A. Cazenava, Eds., Academic Press, 133-169.

_ Pacific Ocean: The roles of boundary- and wind-driven baroclinic Rossby waves. J. Geophys. Res., 107, 3220, doi:10.1029/ 2001JC001131.

Holbrook, N. J., and N. L. Bindoff, 1999: Seasonal temperature variability in the upper southwest Pacific Ocean. J. Phys. Oceanogr., 29, 366-381.

Karoly, D. J., 1989: Southern Hemisphere circulation features associated with El Niño-Southern Oscillation events. J. Climate, 2, 1239-1252.

Kessler, W. S., 1990: Observation of long Rossby waves in the northern tropical Pacific. J. Geophys. Res., 95, 5183-5217.

— wave in the subthermocline equatorial Pacific. J. Phys. Oceanogr., 23, 1192-1207.

Kistler, R., and Coauthors, 2001: The NCEP-NCAR 50-Year Reanalysis: Monthly means CD-ROM and documentation. Bull. Amer. Meteor. Soc., 82, 247-267.

Lagerloef, S. E., G. T. Mitchum, R. B. Lukas, and P. P. Niiler, 1999: Tropical Pacific near-surface currents estimated from altimetry, wind, and drifter data. J. Geophys. Res., 104, $23313-23326$

Le Traon, P.-Y., F. Nadal, and N. Ducet, 1998: An improved mapping method of multisatellite altimeter data. J. Atmos. Oceanic Technol., 15, 522-534.

McCarthy, M. C., L. D. Talley, and D. Roemmich, 2000: Seasonal to interannual variability from XBT and TOPEX/Poseidon data in the South Pacific subtropical gyre. J. Geophys. Res., 105, 19 535-19 550.

McPhaden, M. J., 1999: Genesis and evolution of the 1997-98 El Niño. Science, 283, 950-954.

Meehl, G. A., 1987: The annual cycle and interannual variability of the tropical Pacific and Indian Ocean regions. Mon. Wea. Rev., 115, 27-50. 
Meyers, G., 1979: On the annual Rossby wave in the tropical North Pacific Ocean. J. Phys. Oceanogr., 9, 663-674.

Mo, K. C., and M. Ghil, 1987: Statistics and dynamics of persistent anomalies. J. Atmos. Sci., 44, 877-901.

Pizarro, O., A. J. Clarke, and S. Van Gorder, 2001: El Niño sea level and currents along the South American coast: Comparison of observations with theory. J. Phys. Oceanogr., 31, 18911903.

Qiu, B., 2002: Large-scale variability in the midlatitude subtropical and subpolar North Pacific Ocean: Observations and causes. J. Phys. Oceanogr., 32, 353-375.

— , and S. Chen, 2004: Seasonal modulations in the eddy field of the South Pacific Ocean. J. Phys. Oceanogr., 34, 1515-1527.

Roemmich, D., J. Gilson, R. Davis, P. Sutton, and S. Wijffels, 2006: Decadal spinup of the South Pacific subtropical gyre. J. Phys. Oceanogr., in press.

Schneider, N., A. J. Miller, and D. W. Pierce, 2002: Anatomy of North Pacific decadal variability. J. Climate, 15, 576-605.

Stammer, D., 1997: Steric and wind-induced changes in TOPEX/ Poseidon large-scale sea surface topography observations. $J$. Geophys. Res., 102, 20 987-21 009.

Strub, P. T., and C. James, 2002: The 1997-1998 oceanic El Niño signal along the southeast and northeast Pacific boundariesAn altimetric view. Progress in Oceanography, Vol. 54, Pergamon, 439-458.
— J. Mesias, V. Montecino, J. Rutllant, and S. Salinas, 1998: Coastal ocean circulation off western South America. The Sea, A. R. Robinson and K. H. Brink, Eds., Regional Studies and Syntheses, Vol. 11, John Wiley and Sons, 273-313.

Sturges, W., and B. G. Hong, 1995: Wind forcing of the Atlantic thermocline along $32^{\circ} \mathrm{N}$ at low frequency. J. Phys. Oceanogr., 25, 1706-1715.

Tomczak, M., and J. S. Godfrey, 1994: Regional Oceanography: An Introduction. Pergamon, 422 pp.

Vega, A., Y. du-Penhoat, B. Dewitte, and O. Pizarro, 2003: Equatorial forcing of inter-annual Rossby waves in the eastern South Pacific. Geophys. Res. Lett., 30, 1197, doi:10.1029/ 2002GL015886.

Vivier, F., K. A. Kelly, and L. Thompson, 1999: The contributions of wind forcing, waves, and surface heating to sea surface height observations in the Pacific Ocean. J. Geophys. Res., 104, $20767-20788$.

White, W., 1977: Annual forcing of baroclinic long waves in the tropical North Pacific Ocean. J. Phys. Oceanogr., 7, 50-61.

Willis, J. K., D. Roemmich, and B. Cornuelle, 2004: Interannual variability in upper ocean heat content, temperature, and thermosteric expansion on global scales. J. Geophys. Res., 109, C12036, doi:10.1029/2003JC002260. 